\title{
BMJ Open Does the use of passive or active consent affect consent or completion rates, or dietary data quality? Repeat cross-sectional survey among school children aged 11-12 years
}

\author{
Suzanne Spence, ${ }^{1}$ Martin White, ${ }^{2,3}$ Ashley J Adamson, ${ }^{1,3}$ John N S Matthews ${ }^{4}$
}

To cite: Spence S, White M, Adamson AJ, et al. Does the use of passive or active consent affect consent or completion rates, or dietary data quality? Repeat crosssectional survey among school children aged 1112 years. BMJ Open 2014;4: e006457. doi:10.1136/ bmjopen-2014-006457

- Prepublication history for this paper is available online. To view these files please visit the journal online (http://dx.doi.org/10.1136/ bmjopen-2014-006457).

Received 24 August 2014 Revised 29 October 2014 Accepted 30 October 2014

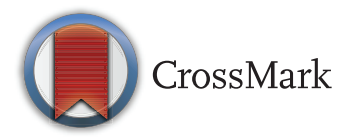

${ }^{1}$ Institute of Health \& Society, Human Nutrition Research Centre, Newcastle University, Newcastle upon Tyne, UK ${ }^{2}$ Institute of Health \& Society, Newcastle University, Newcastle upon Tyne, UK (Visiting Professor)

${ }^{3}$ Fuse, UKCRC Centre for Translational Research in Public Health, Newcastle upon Tyne, UK

${ }^{4}$ School of Mathematics and Statistics, Newcastle University, Newcastle upon Tyne, UK

Correspondence to Professor John NS Matthews; john.matthews@ncl.ac.uk

\section{ABSTRACT}

Objectives: An expectation of research is that participants should give fully informed consent. However, there is also a need to maximise recruitment to ensure representativeness. We explored the impact of passive or active parental consent on consent, completion rates and on dietary data quality in a survey among children aged 11-12 years.

Setting: Six middle schools in North-East England.

Participants: All children aged 11-12 years attending the six middle schools were eligible to participate $(n=1141)$.

Main outcomes: Primary outcomes: whether or not each eligible child's parent gave consent and provided a complete dietary diary; whether or not a child completed their dietary diary but only among children who agreed to participate, and whether or not children providing diaries were classified as an under-reporter or not.

Results: Parents were more likely to consent passively than actively. This difference was greater among the more deprived: OR 16.9 (95\% $\mathrm{Cl} 5.7$ to 50.2) in the least and $129.6(95 \% \mathrm{Cl} 39.9$ to 420.6$)$ in the most deprived quintile (test for interaction: method of consent by level of deprivation, $p=0.02$ ). For all children eligible, completion was more likely if passive consent was used (OR 2.8, 95\% $\mathrm{Cl} 2.2$ to 3.7). When only children who gave consent are considered, completion was less likely when passive rather than active consent was used (OR $0.6,95 \% \mathrm{Cl} 0.4$ to 0.9 ). Completion rate decreased as level of deprivation increased; we found no evidence that the OR for the method of consent varied by level of deprivation. There was no evidence that the quality of dietary data, as measured by an assessment of under-reporting, differed by method of consent (OR $0.8,95 \% \mathrm{Cl} 0.5$ to 1.2 ).

Conclusions: Passive consent led to a higher participation rate and a more representative sample without compromising data quality.

\section{INTRODUCTION}

A central tenet of health and social research is that no one should be recruited to a study without providing informed consent. When

\section{Strengths and limitations of this study}

- We have shown that using passive consent can lead to a higher participation rate and a more representative sample.

- Data quality was not compromised.

- In some circumstances passive consent may offer an ethical alternative to active consent ensuring that all children have an equal opportunity to participate in research.

- It is possible that the differences are due to differences between the two academic years: 2007-2008 and 2009-2010 as the method of consent used was almost totally confounded with year.

the research involves children, the situation is further complicated by the need to obtain consent from the child's legal guardian. While the main concern is that recruits should be fully informed and free to make their choice, all researchers are conscious of the effect of a low recruitment rate on the representativeness of the sample obtained ${ }^{12}$ and thus the generalisability of findings. In any particular context, there may be several equally acceptable ways by which consent may be obtained. If the proportion of those approached who agree to participate varies with the method used, then this is likely to have implications for the usefulness of the inferences that are ultimately made.

We report two dietary surveys of children aged 11-12 years where consent was obtained using two methods: 'passive' and 'active'. For both methods a letter containing information about the study was sent to the child's parent or guardian (parent used throughout) via their school. When passive consent was used the parent was required to return a signed form only if they did not want their 
child to participate, while for active consent a signed form had to be returned giving permission for their child to participate. The use of active consent has some limitations. Letters sent from school are less likely to be returned from children in more deprived areas, ${ }^{3}$ thereby inducing a socioeconomic bias in the sample obtained, while parental apathy ${ }^{3}{ }^{4}$ reduces participation rates. Monaghan et $a \bar{l}^{3}$ and Mellor et a $a \tilde{l}$ showed that parents excluded their child if the research focused on a topic they were currently encountering, for example, dental caries or overweight/obesity. These factors led to low participation rates and biased samples. ${ }^{3}{ }^{6} 7$ Passive consent has the potential to address these issues by increasing participation and including individuals who may otherwise not participate. However, it is important that the data obtained are not of poorer quality. This is particularly relevant for dietary surveys: larger numbers of participants are advantageous only if records are completed. To our knowledge, there is no research that examines the effect of passive or active consent on dietary data quality. This paper uses data from two crosssectional surveys in 11-12 year-olds to explore the effect of passive or active consent across the socioeconomic spectrum on the percentage of children for whom consent was given, who on go to complete dietary diaries and also on the quality of the data that they provide.

\section{METHODS}

\section{Study design and recruitment}

We used data from two cross-sectional surveys that formed part of a series of dietary surveys in middle schools in Northumberland, North-east England. ${ }^{8-11}$ In 2007-2008 and 2009-2010, schools were invited to participate by letter, followed by a presentation at each school. Following the presentation each child was given a parental information letter to take to parents which included information on the study, consent and a form for return to school. In 2007-2008, parents were asked to return the form if they wished their child to participate. In 2009-2010, during preparatory discussions with head teachers it was suggested the consent method should be changed from active to passive. The rationale given by head teachers was that by using active consent we were in effect excluding children whose parents routinely failed to return forms sent by schools as well as children whose parents actively did not wish their child to participate. After obtaining documented support from head teachers and school governors, Newcastle University Ethics Committee granted permission for passive consent to be used in this study (reference 00011/2009). Therefore, in 2009-2010, the consent letter sent to schools asked parents to return the form only if they did not wish their child to participate. There was one exception to this; the head teacher of the smallest school preferred to continue to use active consent: data from this school have been retained in the following analysis. In both surveys, children were able to exclude themselves by not completing the food diaries or by refusing to have anthropometric measurements taken and were free to withdraw from the study at any time.

\section{Categorising socioeconomic status and under-reporting Socioeconomic status}

Anonymised full (7 digit) postcodes were obtained for all eligible children; participating children provided individual postcodes. Socioeconomic status was estimated using the English Index of Multiple Deprivation (IMD) $2007,{ }^{12}$ matched to individual children's postcodes. IMD is based on lower layer super output areas in England and provides a single deprivation score based on seven domains: income, employment, health and disability, education, skills and training, barriers to housing and services, crime and living environment. ${ }^{12}$ This allows areas to be ranked by level of deprivation. ${ }^{12}$ IMD scores were categorised into quintiles relative to national data: quintile 1 included children living in the $20 \%$ least deprived area and quintile 5 included children living in the $20 \%$ most deprived areas.

\section{Under-reporting}

Likely under-reporting was used as a marker of data quality in this study. Dietary data collected were assessed by comparing the child's mean 6 -day energy intake $(2 \times 3$ days; EI) with the predicted basal metabolic rate (BMR). The ratio EI:BMR was used to estimate the number of likely under-reporters; we used values below 1.1 to identify under-reporters. The methods of calculating BMR, ${ }^{13}$ and the cut-off for identifying 'under-reporters' were those used in a previous Northumberland study. ${ }^{10}$

\section{Statistical analysis}

Four logistic regressions were performed. In each, a binary outcome was related to factors indicating IMD quintile, the method of obtaining consent and the interaction of these factors, all adjusted for gender. The outcome in the first analysis was whether or not each eligible child's parent gave consent to be in the study. In the second, the outcome was whether or not each eligible child provided a complete dietary diary. These analyses give estimates of the probability of giving consent and of the probability of providing a complete dietary diary, respectively. The third analysis also considered whether or not a child completed their dietary diary but only among children who agreed to participate in the study: this gives an estimate of the conditional probability that a child provided a complete diary, given that they agreed to participate in the study. The outcome in the final analysis considered data quality, that is, whether or not children providing diaries were classified as an under-reporter or not.

Tests of main effects and interactions are reported along with appropriate ORs and 95\% CIs. All analyses were conducted in R (V.2.14.0) and STATA V.11. 


\section{Ethics}

The amendment to the method of consent from active to passive was granted by Newcastle University Ethics Committee (reference 00011/2009).

\section{RESULTS}

Table 1 shows the number (percentage) of all eligible children for who consent was given (parental), and who completed by method of consent and level of deprivation. Tables 2 and 3 present the ORs and 95\% CI for the method of consent, level of deprivation and the interaction (method of consent by level of deprivation) relevant to the outcomes. Table 4 presents the ORs and 95\% CI for the method of consent and level of deprivation in children who under-reported.

\section{All eligible children}

We found a higher percentage of children's parents consented using passive $(96 \%)$ compared with active consent $(41 \%)$. With passive consent a similar percentage of children's parents consented in each deprivation quintile, whereas when active consent was used the consent rate decreased as level of deprivation increased (table 1). We found evidence of an interaction between the method of consent and level of deprivation for the proportion of children's parents that consented $(\mathrm{p}=0.023)$. When using passive consent, children's parents in IMD quintile 1 (least deprived) were 16.9 times more likely to consent than when using active consent in IMD quintile 1 (OR 16.9, 95\% CI 5.7 to 50.2 ), while in IMD quintile 5 (most deprived) this value rose to 129.6 (95\% CI 39.9 to 420.6 ; table 2$)$.

The method of consent also affected the percentage of children who completed their dietary diaries. A higher percentage of children completed their dietary diaries when consented using passive (53\%) compared with active consent (29\%; table 1; OR 2.8 (95\% CI 2.2 to 3.7 ; $\mathrm{p}<0.001)$. Although there was no evidence that the effect of the method of consent changed with the level of deprivation (test for interaction, $\mathrm{p}=0.73$ ), there was strong evidence that the chance of completing decreased with increasing level of deprivation, with a strong linear trend across the quintiles $(p<0.001$ for linear trend, $p=0.37$ for non-linearity; see table 3 for estimates of the ORs).

\section{Only children for whom consent was given}

For those children whose parents gave consent the percentage completing was lower for passive (55\%) compared with active consent (69\%; OR $0.6,95 \%$ CI 0.4 to $0.9, \mathrm{p}=0.004)$. Again, there was no evidence that the effect of the method of consent varied with level of deprivation $(p=0.99)$, but there was strong evidence that the chance of completing decreased with increasing level of deprivation $(\mathrm{p}<0.001$ for linear trend, $\mathrm{p}=0.21$ for non-linearity). Children in IMD quintile 2 were 0.5 times as likely to complete as children in IMD quintile 1 (least deprived; $95 \%$ CI 0.3 to $0.8, \mathrm{p}=0.01$ ); with children in IMD quintile 5 (most deprived) being 0.2 times as likely to complete as children in IMD quintile $1(95 \%$ CI 0.1 to $0.3, \mathrm{p}<0.001$; table 3 ).

We found no evidence that under-reporting was affected by the method of consent (OR 0.8, 95\% CI 0.5 to $1.2, \mathrm{p}=0.28)$. There was marginal evidence that underreporting was more likely in the most deprived quintile; children in the most deprived quintile were 0.6 times as likely to under-report as children in the least deprived quintile ( $95 \%$ CI 0.3 to $1.0, \mathrm{p}=0.05$; see table 4 for estimates of the ORs).

\section{DISCUSSION}

We found that parents were more likely to consent using passive compared with active consent. The size of the effect of the change in method (active to passive) was greater in more deprived groups. The method of consent also affected the percentage of children who completed: use of passive consent gave a higher completion rate. In contrast, when only children for whom consent was obtained were considered, those children whose parents had actively consented were more likely to complete than children whose parents had passively

\begin{tabular}{|c|c|c|c|c|c|c|c|c|}
\hline & \multicolumn{8}{|c|}{ Method of consent } \\
\hline & \multicolumn{4}{|l|}{ Passive } & \multicolumn{4}{|l|}{ Active } \\
\hline & $\begin{array}{l}\text { All } \\
\text { eligible } \\
n\end{array}$ & $\begin{array}{l}\text { Consented } \\
\text { n (\%) }\end{array}$ & $\begin{array}{l}\text { Completed } \\
\text { n (\%) }\end{array}$ & $\begin{array}{l}\text { Completed as } \\
\text { percentage of } \\
\text { consented } \\
\%\end{array}$ & $\begin{array}{l}\text { All } \\
\text { Eligible } \\
\mathbf{n}\end{array}$ & $\begin{array}{l}\text { Consented } \\
\text { n (\%) }\end{array}$ & $\begin{array}{l}\text { Completed } \\
\text { n (\%) }\end{array}$ & $\begin{array}{l}\text { Completed as } \\
\text { percentage of } \\
\text { consented } \\
\%\end{array}$ \\
\hline $\begin{array}{l}\text { Total } \\
\text { IMD quintile }\end{array}$ & 502 & $484(96)$ & $268(53)$ & 55 & 639 & $264(41)$ & $183(29)$ & 69 \\
\hline 1 (least deprived) & 95 & $91(96)$ & $70(74)$ & 77 & 91 & $52(57)$ & $44(48)$ & 85 \\
\hline 2 & 83 & $78(94)$ & $50(60)$ & 64 & 102 & 49 (48) & 35 (34) & 71 \\
\hline 3 & 66 & $63(95)$ & 41 (62) & 65 & 86 & $36(42)$ & $28(33)$ & 78 \\
\hline 4 & 73 & $70(96)$ & $34(47)$ & 49 & 121 & $52(43)$ & $34(28)$ & 65 \\
\hline 5 (most deprived) & 185 & $182(98)$ & 73 (39) & 40 & 239 & $75(31)$ & $42(18)$ & 56 \\
\hline
\end{tabular}


Table 2 Consent: number (percentage) of all eligible children with OR and $95 \% \mathrm{Cl}$ for method of consent and level of deprivation interaction

\begin{tabular}{|c|c|c|c|c|c|}
\hline & \multicolumn{4}{|c|}{ Method of consent } & \multirow[b]{3}{*}{ OR $(95 \% \mathrm{Cl})^{\star}$} \\
\hline & \multicolumn{2}{|l|}{ Passive } & \multicolumn{2}{|l|}{ Active } & \\
\hline & $\begin{array}{l}\text { All eligible } \\
n\end{array}$ & $\begin{array}{l}\text { Consented } \\
\text { n (\%) }\end{array}$ & $\begin{array}{l}\text { All eligible } \\
n\end{array}$ & $\begin{array}{l}\text { Consented } \\
\mathrm{n}(\%)\end{array}$ & \\
\hline Total & 502 & $484(96)$ & 639 & $264(41)$ & - \\
\hline \multicolumn{6}{|l|}{ IMD quintile } \\
\hline 1 (least deprived) & 95 & $91(96)$ & 91 & $52(57)$ & 16.9 (5.7 to 50.2$)$ \\
\hline 2 & 83 & $78(94)$ & 102 & $49(48)$ & $14.0(5.2$ to 37.9$)$ \\
\hline 3 & 66 & $63(95)$ & 86 & $36(42)$ & 39.2 (8.9 to 172.0$)$ \\
\hline 4 & 73 & 70 (96) & 121 & $52(43)$ & 25.6 (7.6 to 86.7$)$ \\
\hline 5 (most deprived) & 185 & $182(98)$ & 239 & $75(31)$ & 129.6 (39.9 to 420.6 ) \\
\hline
\end{tabular}

* $p$ Value for interaction: method of consent by level of deprivation $p=0.023$ (adjusted for gender)

IMD, Index of Multiple Deprivation.

consented. Nevertheless, the final completion rate was higher when passive consent was used. Although the chance of completing decreased with increasing level of deprivation, we found no evidence that the OR for the effect of the method of consent varied with the level of deprivation. We found no evidence that the quality of data, as measured by assessment of under-reporting, differed between the methods of consent.

A strength of this study is that we were able to explore the use of two different consent methods in the same six schools as a result of a poor consent rate in a dietary survey in 2007-2008, and after discussions with head teachers of schools who expressed the opinion that we were excluding children by using active consent. A limitation is our classification of socioeconomic status. Socioeconomic status was estimated using the Index of Multiple Deprivation, which does not measure individual levels of deprivation, and may lead to misclassification bias. ${ }^{14}$ In this study we assumed that the differences were due to the methods of consent. As the method of consent used was

Table 3 Completion: OR and $95 \% \mathrm{Cl}$ for method of consent and level of deprivation (relative to least deprived) in all eligible children and children for who consent was given

\begin{tabular}{|c|c|c|}
\hline & \multicolumn{2}{|l|}{ Completed } \\
\hline & $\begin{array}{l}\text { All eligible* } \\
\text { OR (95\% Cl)‡ }\end{array}$ & Consented† \\
\hline \multicolumn{3}{|l|}{ Method } \\
\hline $\begin{array}{l}\text { Passive relative to } \\
\text { active }\end{array}$ & 2.8 (2.2 to 3.7$)$ & $0.6(0.4$ to 0.9$)$ \\
\hline \multicolumn{3}{|l|}{ IMD quintile } \\
\hline 1 (least deprived) & - & - \\
\hline 2 & $0.6(0.4$ to 0.9$)$ & 0.5 (0.3 to 0.8$)$ \\
\hline 3 & $0.6(0.4$ to 0.9$)$ & $0.6(0.3$ to 1.1$)$ \\
\hline 4 & $0.3(0.2$ to 0.5$)$ & $0.3(0.1$ to 0.5$)$ \\
\hline 5 (most deprived) & $0.2(0.1$ to 0.3$)$ & $0.2(0.1$ to 0.3$)$ \\
\hline $\begin{array}{l}{ }^{*} p<0.001 \text { for linear treno } \\
t p<0.001 \text { for linear trenc } \\
\ddagger \text { Adjusted for gender. }\end{array}$ & $\begin{array}{l}37 \text { for non-linearity } \\
.21 \text { for non-linearit }\end{array}$ & \\
\hline
\end{tabular}

almost totally confounded with year it is possible that the differences are due to differences between the two academic years: 2007-2008 and 2009-2010; however, one school continued to use the same method of consent in both 2007-2008 and 2009-2010 with a slight fall in participation, highlighting the effect of the method of consent. In addition, the main outcome of interest was to examine the effect of the method of consent used on the percentage of children for whom consent was given, adequately completed their dietary data, and on the quality of data provided. Our study found the use of active consent to be associated with lower participation, a finding previously reported, though not previously in school-based dietary studies. ${ }^{2} 7{ }^{15}$ For example, in a smoking prevention study, by changing the method of consent from active to passive, non-participation reduced by $36 \%{ }^{2}$

There is an opinion that passive consent should be advocated for research where there is low risk to participants. ${ }^{1}$ The UN convention on the Rights of the Child advocates that a child should be involved in decisions and their opinions should be taken into account when adults are making decisions that affect them. ${ }^{16}$ This consideration should also be respected in research, irrespective of the method of consent; research involving children needs to make clear that: participation is voluntary; ${ }^{17}$ there should be no pressure to participate $;{ }^{6}$ they can change their $\operatorname{mind}^{6}$ and leave the study at any point. ${ }^{17}$ If these are made clear to children from the outset of the study, our findings support the use of passive consent in dietary surveys to obtain a higher participation rate, and a more representative sample, without compromising data quality. The implications regarding the use of passive consent in this study relate specifically to dietary surveys. There is potential that passive consent is applicable to other areas of research and settings (ie, the school environment). However, regardless of the type of research or setting the factors noted above need to be adhered to. A high participation rate and a representative sample are paramount to research; our findings show that the use of passive consent helps achieve this. Passive consent led to a 
Table 4 Under-reporting: number (percentage) of children with OR and 95\% Cl for method of consent and level of deprivation

\begin{tabular}{|c|c|c|c|c|c|}
\hline & \multicolumn{4}{|c|}{ Method of consent } & \multirow[b]{3}{*}{ OR $(95 \% \mathrm{Cl})^{\star}$} \\
\hline & \multicolumn{2}{|l|}{ Passive } & \multicolumn{2}{|l|}{ Active } & \\
\hline & $\begin{array}{l}\text { Completed } \\
\text { n }\end{array}$ & $\begin{array}{l}\text { Under-reporters } † \\
\text { n (\%) }\end{array}$ & $\begin{array}{l}\text { Completed } \\
\mathbf{n}\end{array}$ & $\begin{array}{l}\text { Under-reporters } \\
\mathrm{n}(\%)\end{array}$ & \\
\hline Total & $257 \ddagger$ & $116(45)$ & $167+$ & $65(39)$ & $0.8(0.5$ to 1.2$)$ \\
\hline \multicolumn{6}{|l|}{ IMD quintile } \\
\hline 1 (least deprived) & 69 & $29(42)$ & 43 & $18(42)$ & - \\
\hline 2 & 48 & $19(40)$ & 31 & 9 (29) & $1.3(0.7$ to 2.4$)$ \\
\hline 3 & 36 & $13(36)$ & 26 & $7(27)$ & 1.5 (0.8 to 2.9$)$ \\
\hline 4 & 31 & $13(42)$ & 30 & $12(40)$ & 1.0 (0.5 to 2.0$)$ \\
\hline 5 (most deprived) & 73 & $42(58)$ & 37 & $19(51)$ & 0.6 (0.3 to 1.0$)$ \\
\hline
\end{tabular}

higher participation rate and a more representative sample without compromising data quality.

Acknowledgements The authors thank the schools, parents/guardians and children who provided us with extensive data. Thanks to all members of the research advisory group including representatives from the Department of Health, Northumbria county council, Newcastle primary care trust, the School Food Trust (now Children's Food Trust), and Professor Andrew Rugg-Gunn (Professor Emeritus Newcastle University) for his invaluable expertise and guidance. They thank Alison Hossack who collected the 2007-2008 data and Jennifer Delve who assisted in 2009-2010.

Contributors AJA conceived the research and with MW and SS designed the study. SS, Jennifer Delve and Alison Hossack collected the data. SS and JNSM conducted the analyses. SS drafted the manuscript and all authors commented on drafts and approved the final version. AJA is the study guarantor.

Funding This work was undertaken as part of the research programme of the Public Health Research Consortium. The Public Health Research Consortium is funded by the Department of Health (DH) Policy Research Programme. Information about the wider programme of the PHRC is available from http:// phrc.lshtm.ac.uk/. The funders had no role in the study design, data collection or analysis, interpretation of findings, writing of, or the decision to submit for publication. All authors had access to data, and take responsibility for the integrity of the data and the accuracy of the data analysis. AJA is director and MW previous director of Fuse, the Centre for Translational Research in Public Health, a UK Clinical Research Collaboration (UKCRC) Public Health Research Centre of Excellence. Funding for Fuse from the British Heart Foundation, Cancer Research UK, Economic and Social Research Council, Medical Research Council, and the National Institute for Health Research, under the auspices of the UKCRC, is gratefully acknowledged. AJA is funded by the National Institute of Health Research as an NIHR Research Professor. Opinions expressed are not necessarily those of the above named funders.

Competing interests None.

Ethics approval Newcastle University Ethics Committee.

Provenance and peer review Not commissioned; externally peer reviewed.

Data sharing statement No additional data are available.

Open Access This is an Open Access article distributed in accordance with the Creative Commons Attribution Non Commercial (CC BY-NC 4.0) license, which permits others to distribute, remix, adapt, build upon this work non-commercially, and license their derivative works on different terms, provided the original work is properly cited and the use is non-commercial. See: http://creativecommons.org/licenses/by-nc/4.0/

\section{REFERENCES}

1. Junghans $\mathrm{C}$, Feder $\mathrm{G}$, Hemingway $\mathrm{H}$, et al. Recruiting patients to medical research: double blind randomised trial of 'opt-in' versus 'opt-out' strategies. BMJ 2005;331:940.

2. Severson H, Ary D. Sampling bias due to consent procedures with adolescents. Addict Behav 1983;8:433-7.

3. Monaghan N, Jones S, Morgan M. Do parents of children with caries choose to opt-out of positive consent dental surveys in Wales? Br Dent J 2011;210:E1.

4. Dent C, Galaif J, Sussman S, et al. Demographic, psychosocial and behavioral differences in samples of actively and passively consented adolescents. Addict Behav 1993;18:51-6.

5. Mellor J, Rapoport R, Maliniak D. The impact of child obesity on active parental consent in school-based survey research on healthy eating and physical activity. Eval Rev 2008;32:298-312.

6. O'Neill O. Some limits of informed consent. J Med Ethics 2003;29:4-7.

7. Lacy K, Kremer P, de Silva-Sanigorski A, et al. The appropriateness of opt-out consent for monitoring childhood obesity in Australia. Pediatr Obes 2012;7:e62-7.

8. Adamson AJ, Rugg-Gunn AJ, Butler TJ, et al. Nutritional intake, height and weight of 11-12-year-old Northumbrian children in 1990 compared with information obtained in 1980. Br J Nutr 1992;68:543-63.

9. Adamson AJ, Rugg-Gunn AJ, Butler TJ, et al. The contribution of foods from outside the home to the nutrient intake of young adolescents. J Hum Nutr Diet 1996;9:55-68.

10. Fletcher ES, Rugg-Gunn AJ, Matthews JN, et al. Changes over 20 years in macronutrient intake and body mass index in 11- to 12-year old adolescents living in Northumberland. Br J Nutr 2004;92:321-33.

11. Rugg-Gunn AJ, Fletcher ES, Matthews JN, et al. Changes in consumption of sugars by English adolescents over 20 years. Public Health Nutr 2007;10:354-63.

12. Communities and Local Government Indices of Deprivation. 2007. http://webarchive.nationalarchives.gov.uk/+/http://www.communities. gov.uk/communities/neighbourhoodrenewal/deprivation/ deprivation 07/ (accessed 30 Jun 2011).

13. Schofield WN. Predicting basal metabolic rate, new standards and review of previous work. Hum Nutr Clin Nutr 1985;39(Suppl 1):5-41.

14. Pockett R, Adlard N, Carroll S, et al. Paediatric hospital admissions for rotavirus gastroenteritis and infectious gastroenteritis of all causes in England: an analysis of correlation with deprivation. Curr Med Res Opin 2011;27:777-84.

15. Nellist K, Coats K, Friedrichs M. Using a representative sample of elementary school students to determine the statewide prevalence of childhood overweight and obesity in Utah. Prev Chronic Dis 2009;6: A136.

16. UNICEF The UN Conventions on the Rights of the Child. http://www unicef.org/crc/files/Rights_overview.pdf (accessed 23 Sep 2014).

17. Ross J, Sundberg E, Flint K. Informed consent in school health research: why, how and making it easy. $J$ Sch Health 1999;69:171-6. 